\title{
Effectiveness of mRNA-1273 against SARS-CoV-2 omicron and delta variants
}

Authors: Hung Fu Tseng ${ }^{1,2}$, Bradley K. Ackerson ${ }^{1}$, Yi Luo ${ }^{1}$, Lina S. Sy ${ }^{1}$, Carla A. Talarico $^{3}$, Yun Tian ${ }^{1}$, Katia J. Bruxvoort ${ }^{4}$, Julia E. Tubert ${ }^{1}$, Ana Florea ${ }^{1}$, Jennifer H. Ku ${ }^{1}$, Gina S. Lee ${ }^{1}$, Soon Kyu Choi ${ }^{1}$, Harpreet S. Takhar ${ }^{1}$, Michael Aragones ${ }^{1}$ and Lei Qian ${ }^{1}$

Affiliations: ${ }^{1}$ Department of Research and Evaluation, Kaiser Permanente Southern California, Pasadena, CA, USA. ${ }^{2}$ Department of Health Systems Science, Kaiser

Permanente Bernard J. Tyson School of Medicine, Pasadena, CA, USA. ${ }^{3}$ Moderna, Inc., Cambridge, MA, USA. ${ }^{4}$ Department of Epidemiology, University of Alabama at Birmingham, Birmingham, AL, USA

${ }^{*}$ Corresponding Author: Hung Fu Tseng, Department of Research and Evaluation, Kaiser Permanente Southern California, 100 S Los Robles, Pasadena, CA 91101

Phone: (626) 564-3451

Email: $\underline{\text { Hung-Fu.X.Tseng@kp.org }}$ 
medRxiv preprint doi: https://doi.org/10.1101/2022.01.07.22268919; this version posted January 21, 2022. The copyright holder for this preprint (which was not certified by peer review) is the author/funder, who has granted medRxiv a license to display the preprint in perpetuity.

All rights reserved. No reuse allowed without permission.

\section{Abstract}

The SARS-CoV-2 omicron (B.1.1.529) variant is highly transmissible with potential for immune escape. Thus, we conducted a matched case-control study to evaluate the real-world vaccine effectiveness (VE) of mRNA-1273 against infection and hospitalization with omicron or delta in a large, diverse Southern California population. The study included 26,683 SARS-CoV-2 test positive cases with variant determined by spike gene status (16\% delta, $84 \%$ omicron). The 2 -dose VE against omicron infection was $42.8 \%(95 \% \mathrm{Cl}, 33.8 \%-50.7 \%)$ and declined quickly thereafter. The 3-dose VE was $94.0 \%(92.3 \%-95.4 \%)$ and $67.7 \%(65.5 \%-69.7 \%)$ against delta and omicron infection, respectively, and $21.7 \%(0.0 \%-45.0 \%)$ against omicron infection in immunocompromised individuals. The 3-dose VE against hospitalization with delta or with omicron was above 99\%. Our findings demonstrate high and durable 3-dose effectiveness of mRNA-1273 against delta infection but lower effectiveness against omicron infection, particularly among immunocompromised people.

However, 3 doses of mRNA-1273 were highly effective against hospitalization with either delta or omicron. 
The recently emerged severe acute respiratory syndrome coronavirus 2 (SARS-CoV-2) omicron (B.1.1.529) variant contains multiple novel spike (S) protein mutations, raising concerns about escape from naturally acquired or vaccine-elicited immunity. ${ }^{1}$ Several in vitro studies reported reduced vaccine-induced neutralization activity against omicron. ${ }^{2,3}$ Specifically, sera from individuals vaccinated with 2 doses of mRNA coronavirus disease 2019 (COVID-19) vaccines, including mRNA-1273 (Moderna COVID-19 vaccine), showed substantial reductions in neutralization activity against omicron compared with wild-type SARS-CoV-2., ${ }^{2,4}$ However, an mRNA-1273 booster increased neutralization activity against omicron, albeit lower than wild-type. ${ }^{2,3}$ We previously reported high and durable vaccine effectiveness (VE) of mRNA-1273 against infection and hospitalization from COVID-19 caused by other emerging SARS-CoV-2 variants, including delta (B.1.617.2) ${ }^{6}$ Limited data are available on real-world VE of mRNA-1273 against omicron.

As omicron has a deletion at positions 69-70, omicron-positive specimens exhibit Sgene target failure (SGTF). To provide timely results for these analyses, we used SGTF as a marker for omicron in specimens collected during December 2021. The US Food and Drug Administration (FDA) and World Health Organization advised that SGTF from select COVID-19 RT-PCR assays, including the Thermo Fisher TaqPath ${ }^{\text {TM }}$ COVID-19 Combo kits, can be used as a screening method for omicron; ${ }^{7,8}$ SGTF has served as a proxy in the United Kingdom for identifying omicron. ${ }^{9,10}$ In Southern California, where delta was the dominant strain before omicron ${ }^{11}$ and the proportion of SGTF among SARS-CoV-2 positive specimens increased from $1.2 \%$ to $94.1 \%$ from $12 / 06 / 2021$ to 12/31/2021, SGTF can be used as a proxy for omicron, while positive specimens 
negative for SGTF can be considered delta. Herein, we report VE of mRNA-1273 against infection and hospitalization with omicron and delta within the Kaiser Permanente Southern California (KPSC) health care system in the United States.

\section{Results}

The study included 26,683 cases with SGTF status available; $11,483(43.0 \%)$ individuals were unvaccinated (2,883 delta, 8,600 omicron), and 15,200 (57.0\%) were vaccinated (1,431 delta, 13,769 omicron; 416 vaccinated with 1 dose, 12,029 vaccinated with 2 doses, 2,755 vaccinated with 3 doses). The flow chart depicting selection steps is provided in Supplementary Fig. 1. The distribution of covariates by test outcomes, separated by variant type, is summarized in Table 1 (2-dose and 3-dose analyses) and Supplementary Table 1 (1-dose analysis).

Omicron cases more frequently had a history of COVID-19 than delta cases. In the 2dose and 3-dose analyses, $13.6 \%$ and $15.4 \%$ of omicron cases in the 2-dose and 3dose analyses, respectively, had a history of COVID- 19 versus $2.5 \%$ and $3.0 \%$ of delta cases (Table 1).

Table 2 shows VE against delta and omicron infection or hospitalization. Overall, the 1dose VE was $55.6 \%$ (95\% Cl: 38.8-67.8\%) and 20.0\% (8.9-29.8\%), the 2-dose VE was $60.7 \%(56.6-64.3 \%)$ and $15.5 \%(12.2-18.7 \%)$, and the 3-dose VE was $94.0 \%$ (92.3$95.4 \%)$ and $67.7 \%(65.5-69.7 \%)$ against delta and omicron infection, respectively. In analyses of 2-dose VE against delta infection by time since receipt of dose 2, VE at 14-90 days was $79.8 \%$ (67.4-87.5\%) and subsequently declined, with VE of $66.3 \%$ (56.6-73.8\%) at $91-180$ days, $61.2 \%(56.9-65.0 \%)$ at $181-270$ days and $57.5 \%$ (50.4- 
$63.6 \%$ ) at $>270$ days (Table 2, Fig. 1). The 2-dose VE against omicron infection was $42.8 \%(33.8-50.7 \%)$ at $14-90$ days and declined quickly to $23.0 \%(15.8-29.6 \%)$ at $91-$ 180 days, $15.6 \%(12.1-19.1 \%)$ at $181-270$ days and $8.6 \%(3.3-13.6 \%)$ at $>270$ days. The 3-dose VE against delta infection was 92.9\% (91.2-94.3\%) if dose 3 was received after October 20, 2021, and $87.8 \%(78.5-93.1 \%)$ if dose 3 was received on or before October 20, 2021. For vaccinated cases, the median number of days from vaccination to positive test date was 41 and 113 days if dose 3 was received after October 20, 2021 , or on and before that day, respectively. However, the 3-dose VE against omicron infection was 67.9\% (65.8-69.9\%) if dose 3 was received after October 20, 2021 (for vaccinated cases, median number of days from vaccination to positive test date was 41 days), and 49.5\% (40.4-57.3\%) if received on or before October 20, 2021 (for vaccinated cases, median number of days from vaccination to positive test date was 111 days). These estimates were similar in analyses excluding individuals who were immunocompromised, except that the 3-dose VE against omicron infection increased to $54.8 \%(44.9-62.9 \%)$ among immunocompetent individuals who received dose 3 on or before 10/20/21 (Table 2, Fig. 2).

The VE of 2 and 3 doses against hospitalization with delta were both more than $98 \%$, while they were $74.8 \%(2.4-93.5 \%)$ and $99.7 \%$ (82.2-100.0\%) against hospitalization with omicron (Table 2). Notably, all four individuals hospitalized with omicron despite receipt of three mRNA-1273 doses were more than 60 years with chronic diseases and one was also immunocompromised (data not shown).

Table 3 presents the 3-dose VE against infection by subgroups. The 3-dose VE against delta infection was $>92 \%$ across age, sex and race/ethnicity groups but lower in the 
immunocompromised population (75.0\% [38.3-89.9\%]). The 3-dose VE against omicron infection was $68.6 \%(66.3-70.7 \%)$ in those aged $<65$ years and $63.6 \%(53.8 \%-71.4 \%)$ in those aged $\geq 65$ years and only $21.7 \%(0.0-45.0 \%)$ in the immunocompromised population compared to $68.2 \%(66.1-70.2 \%)$ in the immunocompetent population. The 3-dose VE against omicron infection among those who had no history of COVID-19 was $69.1 \%(66.9 \%, 71.3 \%)$ in those aged $<65$ years, and $63.9 \%(53.8 \%, 71.8 \%)$ in those aged $\geq 65$ years (data not shown).

\section{Discussion}

We evaluated the effectiveness of mRNA-1273 against the highly mutated omicron variant in a socio-demographically diverse population in a real-world setting. Between December 6, 2021, and December 31, 2021, the rapidly increasing proportion of omicron-positive specimens indicated unprecedented transmissibility and raised concerns over protection conferred by currently authorized or licensed COVID-19 vaccines. Our study demonstrates that while VE of 2 doses of mRNA-1273 against delta infection is high and wanes slowly, consistent with our previous findings, ${ }^{6,12}$ the 2-dose VE against omicron infection is inadequate, providing only modest protection of $42.8 \%$ within 3 months of vaccination and diminishing quickly thereafter. In addition, while the 3-dose VE against delta infection is high and durable, that against omicron is lower. Nevertheless, the point estimate (>50\%) and lower bound of the $95 \% \mathrm{Cl}(>30 \%)$ still meet the US FDA criteria for emergency use authorization for 2 doses of COVID-19 vaccines. ${ }^{13}$ Also, this VE is similar to the 2-dose vaccine efficacy against asymptomatic infection observed in the phase 3 clinical trial $(63.0 \%[56.6-68.5 \%]) .{ }^{14}$ The VE of 3 
doses of mRNA-1273 against omicron infection is poor among individuals who are immunocompromised. While 2-dose VE against hospitalization with omicron is lower compared to that with delta, 3-dose VE is nearly $100 \%$ against hospitalization with either variant. Taken together, these data suggest that third (booster) doses may be needed $<6$ months after dose 2 in immunocompetent individuals and that 3 doses may be inadequate to protect against omicron infection in individuals who are immunocompromised. Furthermore, the data highlight the potential need for periodic adjustment of vaccines to target circulating variants, including omicron, that have evolved to escape current vaccine-induced immunity.

While there are limited prior data on VE of 2 or 3 doses of mRNA-1273 vaccine against infection or hospitalization with omicron, a preliminary analysis from Denmark found an initial VE of 2 doses of mRNA-1273 against omicron infection of $36.7 \%$ that waned quickly, similar to our findings. ${ }^{15}$ An early report by Andrews et al ${ }^{16}$ found waning of 2dose protection with an initial VE of 2 doses of BNT162b2 against symptomatic omicron infection of $88 \%(65.9-95.8 \%) 2-9$ weeks after dose 2 that declined to $34-37 \%$ (95\% Cls ranging from -5 to $59.6 \%$ ) 15 or more weeks after dose 2 , but increased to $75.5 \%$ (56.1-86.3\%) a median of 41 days (range 14-72 days) after a BNT162b2 booster. Collie et $\mathrm{al}^{17}$ found that the VE of 2 doses of BNT162b2 against hospitalization during a proxy omicron period was $70 \%$ at least 14 days after receipt of dose 2. In England, after a primary course of BNT162b2 vaccine, VE against omicron infection was initially $70 \%$ after a BNT162b2 booster, dropping to $45 \%$ after $\geq 10$ weeks, but stayed around 70 $75 \%$ for up to 9 weeks after an mRNA-1273 booster. $^{10}$ 
A growing number of reports indicate that omicron disease is less severe than delta disease, resulting in a lower risk of hospitalization. ${ }^{1,18}$ This may reflect greater replication of omicron in the upper versus lower respiratory tract, which may also contribute to more efficient transmission, resulting in increased absolute ${ }^{19}$ numbers of hospitalizations. Booster vaccination has the potential to decrease hospital burden and improve outcomes. ${ }^{20}$ While the sample size and follow-up period were not sufficient in our study or other studies to assess potential waning VE against hospitalization with omicron, our results of waning VE against omicron infection after dose 3 of mRNA-1273 underscores the importance of monitoring VE against hospitalization with omicron. This study provides novel data complementing recent reports of the effectiveness of other COVID-19 vaccines against omicron infection and has several strengths and limitations. Testing for SARS-CoV-2 infection was readily available among KPSC members, including drive-through testing and self-scheduled test appointments. Furthermore, we used a highly specific and sensitive RT-PCR test and monitored variant proportions at KPSC, allowing us to quickly assess VE of mRNA-1273 against omicron. Attributes associated with testing behavior or health-seeking behavior can be differential by exposure status, leading to potential bias. To control for these potential differences, we adjusted for history of SARS-CoV-2 molecular testing, history of COVID19, prior health care utilization and other chronic diseases in the models. Although potential residual confounding or detection bias could remain, they were not likely to reverse the conclusion of the study. Second, we considered all SGTF specimens as omicron, rather than specifying a Ct value threshold, although this may have overestimated omicron detection. Our rate of SGTF closely mirrored regional trends in 
omicron emergence from the Centers for Disease Control and Prevention (CDC). ${ }^{11}$ Furthermore, based on whole genome sequencing results received for a subset of 955 positive specimens, we confirmed that all 319 cases exhibiting SGTF were omicron, and 632 of the 636 SGTF negative cases were delta (kappa 0.991). Third, this study was representative of a large, diverse racial, ethnic and socioeconomic population in Southern California but may be less representative of other populations. However, analysis of the effectiveness of mRNA-1273 against delta and omicron in parallel provided an internal comparator that put results in context. ${ }^{12}$ Fourth, some individuals who were immunocompetent and who received a third dose before the October 21 , 2021, Advisory Committee on Immunization Practices (ACIP) recommendation may have received a $100-\mu \mathrm{g}$ dose rather than a $50-\mu \mathrm{g}$ booster dose of mRNA-1273. However, we were not able to clearly assess the difference, as dosage information was not available from external vaccination records. Finally, the number of hospitalized individuals included was too small to draw definitive conclusions regarding VE and durability of 3 doses in preventing hospitalization. Long-term follow-up is needed to evaluate the durability of both $100-\mu \mathrm{g}$ and $50-\mu \mathrm{g}$ booster doses in preventing infection and hospitalization.

In conclusion, this study of mRNA-1273 found waning 2-dose but high 3-dose VE against delta infection, low 2-dose and 3-dose VE against omicron infection, modest 2dose VE against hospitalization with omicron, and excellent 3-dose VE against hospitalization with either variant. Protection against omicron infection wanes within 3 months after dose 2, suggesting a need for a shorter interval between second and booster doses. Lack of protection against omicron infection in the immunocompromised 
population underscores the importance of the recommended fourth dose (booster) for this population. Continued monitoring of VE against omicron infection and hospitalization in immunocompetent and immunocompromised individuals and surveillance for the emergence of newer SARS-CoV-2 variants are warranted to inform future vaccination strategies.

\section{Online Methods}

Study setting. KPSC is an integrated health care system that provides care to more than 4.6 million socio-demographically diverse health plan members at 15 hospitals and associated medical offices across Southern California. Comprehensive electronic health records (EHRs) used for this study included information on demographics, immunizations, diagnoses, laboratory tests, procedures and pharmacy records. KPSC began administering mRNA-1273 on 12/18/2020. Outside COVID-19 vaccinations were imported into members' EHRs daily from external sources, including the California Immunization Registry, Care Everywhere (system on the Epic EHR platform that allows health care systems to exchange members' medical information), claims (eg, retail pharmacies) and self-report by members (with valid documentation).

Laboratory methods. Molecular diagnostic testing for SARS-CoV-2 is available to members who request it for any reason, before procedures and hospital admissions, with and without symptoms. Specimens were primarily collected using nasopharyngeal/oropharyngeal swabs (for symptomatic individuals) or saliva (for asymptomatic individuals). Specimens were tested using RT-PCR TaqPath COVID-19 High-Throughput Combo Kit (Thermo Fisher Scientific). SGTF was defined as a RTPCR test in which N and ORF1ab genes were detected (Ct values $<37$ ), but $\mathrm{S}$ gene was 
not detected. Specimens with SGTF were considered to be omicron, whereas positive specimens without SGTF were considered to be delta.

Study design. In this case-control study, cases included individuals who tested positive by the RT-PCR TaqPath COVID-19 kit, had specimens collected between 12/6/2021 and $12 / 31 / 2021$, were aged $\geq 18$ years, and had $\geq 12$ months of KPSC membership before the specimen collection date (for accurate ascertainment of exposure status and covariates). Individuals were excluded if they received a COVID-19 vaccine other than mRNA-1273, any dose of mRNA-1273 <14 days before the specimen collection date, 2 or 3 doses of mRNA-1273 <24 days apart from previous dose or $>3$ doses of mRNA1273 prior to the specimen collection date. Additional exclusions included a positive SARS-CoV-2 test or COVID-19 diagnosis code $\leq 90$ days before the specimen collection date. COVID-19 hospitalization included hospitalization with a SARS-CoV-2-positive test or hospitalization $\leq 7$ days after a SARS-CoV-2-positive test. COVID-19 hospitalization was confirmed by manual chart review conducted by a physician investigator (B.K.A.) to verify the presence of severe COVID-19 symptoms. Controls included all individuals who tested negative with specimens collected between $12 / 6 / 2021$ and $12 / 31 / 2021$ and with the same age and membership requirement as cases. Randomly sampled controls were $2: 1$ matched to cases by age (18-44 years, 45-64 years, 65-74 years and $\geq 75$ years), sex, race/ethnicity (non-Hispanic White, nonHispanic Black, Hispanic, non-Hispanic Asian and other/unknown) and specimen collection date. Matching was conducted separately for the 1-, 2-, and 3-dose VE analysis. To accommodate variation in real-world practice, analyses did not require 
dose 3 to be $\geq 6$ months from dose 2 , as some members received dose 3 at a shorter interval in this study.

Exposure. The exposure of interest was 1, 2 or 3 doses of mRNA-1273. Dose 3 in this analysis included both the $100-\mu \mathrm{g}$ additional primary dose in individuals who were immunocompromised, as well as the $50-\mu \mathrm{g}$ and 100-ug booster dose in adults.

Covariates. Demographic and clinical covariates were extracted from EHRs. ${ }^{12}$ Variables assessed included socioeconomic status (Medicaid, neighborhood median household income), medical center area, pregnancy status, KPSC physician/employee status, smoking, body mass index, Charlson comorbidity score, autoimmune conditions, chronic diseases (kidney, heart, lung, and liver disease and diabetes), frailty index and immunocompromised status. To account for potential differences in care-seeking or test-seeking behaviors, the following variables were also adjusted for: health care utilization (virtual, outpatient, emergency department and inpatient encounters), preventive care (other vaccinations, screenings and wellness visits), history of SARSCoV-2 molecular test performed from 3/1/2020 to specimen collection date (irrespective of result) and history of COVID-19 (positive SARS-CoV-2 molecular test or a COVID-19 diagnosis code) from 3/1/2020 to specimen collection date.

Statistical analyses. Characteristics of cases and controls for each analysis were compared by using the $\mathrm{x}^{2}$ test or Fisher exact test for categorical variables and twosample $t$ test or Wilcoxon rank sum test for continuous variables. The distribution of variant type by vaccination status was tabulated. Conditional logistic regression was used to estimate the adjusted odds ratios (OR) and 95\% confidence intervals $(\mathrm{Cl})$ for vaccination against infection and hospitalization with delta or omicron. Analyses were 
adjusted for potential confounders, determined by scientific relevance or by absolute standardized differences $(A S D)>0.1$ and $P$ value $<0.1$. Unconditional logistic regression with additional adjustment of matching factors in the model was used when matched sets needed to be broken for certain subgroup analyses or when the conditional model failed to converge. VE (\%) was calculated as (1-adjusted OR) $\times 100$. As VE is a prevented fraction, which is a percentage ranging between $0 \%$ and $100 \%$, the point estimate and its $\mathrm{Cl}$ cannot be a negative value.

We also assessed 2-dose and 3-dose VE against delta or omicron infection by time since receipt of mRNA-1273 dose 2 or 3 (for 2-dose VE: 14-90 days, 91-180 days, 181270 days, and $>270$ days; for 3 -dose VE: on or before $10 / 20 / 2021$ versus on or after 10/21/2021). 10/21/2021 was chosen since it was the date the ACIP recommended a $50-\mu \mathrm{g}$ booster of mRNA-1273 for individuals who completed their primary series $\geq 6$ months prior. ${ }^{21,22}$ As more immunocompromised persons might have received dose 3 before the October 2021 recommendation, we conducted a separate analysis that excluded individuals who were immunocompromised to assess durability of protection of 3 doses in immunocompetent individuals. We also evaluated 3-dose VE in select subgroups, including by age (<65, $\geq 65$ years), sex, race/ethnicity (Hispanic, NonHispanic and others) and immunocompromised status (yes, no). As VE in individuals with a history of COVID-19 is different from those without, ${ }^{6}$ we also evaluated 3 -dose VE against omicron infection, stratified by age ( $<65$ years and $\geq 65$ years), among individuals with no history of COVID-19. SAS 9.4 was used for analyses. The study was approved by KPSC Institutional Review Board. All study staff with access to protected health information were trained in procedures to protect the confidentiality of KPSC 
medRxiv preprint doi: https://doi.org/10.1101/2022.01.07.22268919; this version posted January 21, 2022. The copyright holder for this preprint (which was not certified by peer review) is the author/funder, who has granted medRxiv a license to display the preprint in perpetuity.

All rights reserved. No reuse allowed without permission.

member data. A waiver of informed consent was obtained as this is an observational study of authorized and recommended Moderna COVID-19 vaccine administered in the course of routine clinical care. To facilitate the conduct of this study, a waiver was obtained for written HIPAA authorization for research involving use of the EHR. 


\section{Data availability}

Individual-level data reported in this study are not publicly shared. Upon request, and subject to review, KPSC may provide the deidentified aggregate-level data that support the findings of this study. Deidentified data may be shared upon approval of an analysis proposal and a signed data access agreement.

\section{Acknowledgments}

Medical writing and editorial assistance were provided by Srividya Ramachandran, PhD, and Jared Mackenzie, PhD, of MEDiSTRAVA in accordance with Good Publication Practice (GPP3) guidelines, funded by Moderna, Inc., and under the direction of the authors. Laboratory and database support were provided at KPSC by Lee Childs, Julie Stern, Joy Gelfond, Radha Bathala, Kourtney Kottmann, Ana Acevedo, Elmer Ayala, Samantha Quinones, Samantha Baluyot, Errol Lopez and Don McCarthy. The authors thank the KPSC Lab Leadership and Technician Team for their support of this study. The authors would like to acknowledge Helix OpCo, LLC, for their whole genome sequencing of SARS-CoV-2 specimens. The authors thank the patients of Kaiser Permanente for their partnership with us to improve their health. Their information, collected through our electronic health record systems, leads to findings that help us improve care for our members and can be shared with the larger community. Julie Vanas, Moderna, Inc., provided critical operations support and Yamuna Paila, Moderna, Inc., provided critical input on specimen sequencing.

\section{Author contributions}


H.F.T, L.S.S, L.Q, K.J.B, and C.A.T were involved in the study concept and design, as well as acquisition, analysis, or interpretation of data (including B.K.A). H.F.T and B.K.A drafted the manuscript. Y.L, L.S.S, C.A.T, Y.T, K.J.B, J.E.T, A.F, J.H.K, G.S.L, S.K.C, H.S.T, M.A, and L.Q critically revised the manuscript for important intellectual content. L.Q, Y.L, Y.T, and J.E.T conducted the statistical analyses. L.S.S, C.A.T, G.S.L, M.A, S.K.C, and H.S.T provided administrative, technical, or material support. C.A.T and H.F.T obtained funding and provided supervision.

\section{Competing interests}

All authors have completed the ICMJE uniform disclosure form at www.icmje.org/coi_disclosure.pdf and declare the following: H.F.T., B.K.A., Y.L., L.S.S., Y.T., J.E.T., A.F., J.H.K., G.S.L., S.K.C., H.S.T., M.A. and L.Q. are employees of Kaiser Permanente Southern California, which has been contracted by Moderna, Inc., to conduct this study. K.J.B. is an adjunct investigator at Kaiser Permanente Southern California. C.A.T. is an employee of and a shareholder in Moderna, Inc. H.F.T. received funding from GlaxoSmithKline and Seqirus unrelated to this manuscript; H.F.T. also served in advisory boards for Janssen and Pfizer Inc. B.K.A. received funding from GlaxoSmithKline, Dynavax, Seqirus, Pfizer Inc. and Genentech for work unrelated to this study and has served on advisory boards for GlaxoSmithKline. Y.L. received funding from GlaxoSmithKline, Seqirus and Pfizer Inc. unrelated to this manuscript. L.S.S. received funding from GlaxoSmithKline, Dynavax and Seqirus unrelated to this manuscript. Y.T. received funding from GlaxoSmithKline unrelated to this manuscript. J.E.T. received funding from Pfizer Inc. unrelated to this manuscript. A.F. received funding from Pfizer Inc., GlaxoSmithKline and Gilead unrelated to this manuscript. 
medRxiv preprint doi: https://doi.org/10.1101/2022.01.07.22268919; this version posted January 21, 2022. The copyright holder for this preprint (which was not certified by peer review) is the author/funder, who has granted medRxiv a license to display the preprint in perpetuity.

All rights reserved. No reuse allowed without permission.

J.H.K. received funding from GlaxoSmithKline unrelated to this manuscript. G.S.L. received funding from GlaxoSmithKline unrelated to this manuscript. S.K.C. received funding from Pfizer Inc. and Pancreatic Cancer Action Network unrelated to this manuscript. H.S.T. received funding from GlaxoSmithKline, Pfizer Inc., ALK and Wellcome unrelated to this manuscript. M.A. received funding from Pfizer Inc. unrelated to this manuscript. L.Q. received funding from GlaxoSmithKline and Dynavax unrelated to this manuscript.

\section{Funding}

This study was funded by Moderna, Inc. 


\section{References}

1. Wolter, N., et al. Early assessment of the clinical severity of the SARS-CoV-2 Omicron variant in South Africa. medRxiv, 2021.2012.2021.21268116 (2021).

2. Garcia-Beltran, W.F., et al. mRNA-based COVID-19 vaccine boosters induce neutralizing immunity against SARS-CoV-2 Omicron variant. Cell.

3. Nicole A. Doria-Rose, X.S., Stephen D Schmidt, Sijy O’Dell, Charlene McDanal, Wenhong Feng, Jin Tong, Amanda Eaton, Maha Maglinao, Haili Tang, Kelly E. Manning, Venkata-Viswanadh Edara, Lilin Lai, Madison Ellis, Kathryn Moore, Katharine Floyd, Stephanie L. Foster, Robert L. Atmar, Kirsten E. Lyke, Tongqing Zhou, Lingshu Wang, Yi Zhang, Martin R Gaudinski, Walker P Black, Ingelise Gordon, Mercy Guech, Julie E Ledgerwood, John N Misasi, Alicia Widge, Paul C. Roberts, John Beigel, Bette Korber, Rolando Pajon, John R. Mascola, Mehul S. Suthar, David C. Montefiori. Booster of mRNA-1273 Strengthens SARS-CoV-2 Omicron Neutralization. MedRxiv medRxiv 2021.12.15.21267805(2021).

4. Cele, S., et al. SARS-CoV-2 Omicron has extensive but incomplete escape of Pfizer BNT162b2 elicited neutralization and requires ACE2 for infection. medRxiv (2021).

5. Wilhelm, A., et al. Reduced Neutralization of SARS-CoV-2 Omicron Variant by Vaccine Sera and Monoclonal Antibodies. medRxiv, 2021.2012.2007.21267432 (2021).

6. Bruxvoort, K.J., et al. Real-world effectiveness of the mRNA-1273 vaccine against COVID-19: Interim results from a prospective observational cohort study. Lancet Reg Health Am, 100134 (2021).

7. United States Food and Drug Administration. SARS-CoV-2 Viral Mutations: Impact on COVID-19 Tests Vol. 2022 (2021).

8. WHO. Enhancing Readiness for Omicron (B.1.1.529): Technical Brief and Priority Actions for Member States. https://www.who.int/publications/m/item/enhancing- 
medRxiv preprint doi: https://doi.org/10.1101/2022.01.07.22268919; this version posted January 21, 2022. The copyright holder for this preprint (which was not certified by peer review) is the author/funder, who has granted medRxiv a license to display the preprint in perpetuity.

All rights reserved. No reuse allowed without permission.

readiness-for-omicron-(b.1.1.529)-technical-brief-and-priority-actions-for-member-states. (2021).

9. Public Health England. Investigation of novel SARS-CoV-2 variant: variant of convern 202012/01. (2020).

10. Public Health England. SARS-CoV-2 variants of concern and variants under investigation in England (2021).

11. United States Centers for Disease Control and Prevention. COVID Data Tracker: Variant Proportions. Vol. 2022.

12. Bruxvoort, K.J., et al. Effectiveness of mRNA-1273 against delta, mu, and other emerging variants of SARS-CoV-2: test negative case-control study. BMJ 375, e068848 (2021).

13. Food and Drug Administration. Emergency Use Authorization for Vaccines to Prevent COVID-19: Guidance for Industry. (2021).

14. El Sahly, H.M., et al. Efficacy of the mRNA-1273 SARS-CoV-2 Vaccine at Completion of Blinded Phase. N Engl J Med 385, 1774-1785 (2021).

15. Hansen, C.H., et al. Vaccine effectiveness against SARS-CoV-2 infection with the Omicron or Delta variants following a two-dose or booster BNT162b2 or mRNA-1273 vaccination series: A Danish cohort study. medRxiv, 2021.2012.2020.21267966 (2021).

16. Andrews, N., et al. Effectiveness of COVID-19 vaccines against the Omicron (B.1.1.529) variant of concern. medRxiv, 2021.2012.2014.21267615 (2021).

17. Collie, S., Champion, J., Moultrie, H., Bekker, L.G. \& Gray, G. Effectiveness of BNT162b2 Vaccine against Omicron Variant in South Africa. N Engl J Med 10.1056/NEJMc2119270 (2021).

18. Ferguson N, et al. Report 49: Growth, population distribution and immune escape of Omicron in England (Imperial College London, 2021). 
medRxiv preprint doi: https://doi.org/10.1101/2022.01.07.22268919; this version posted January 21, 2022. The copyright holder for this preprint

(which was not certified by peer review) is the author/funder, who has granted medRxiv a license to display the preprint in perpetuity.

All rights reserved. No reuse allowed without permission.

19. Chan, M.C.W., et al. SARS-CoV-2 Omicron variant replication in human respiratory tract ex vivo. Research Square 10.21203/rs.3.rs-1189219/v1 (2021).

20. French $\mathrm{G}$, et al. Impact of hospital strain on excess deaths during the COVID-19 pandemic - United States, July 2020-July 2021. MMWR Morb Mortal Wkly Rep 70, 1613-1616 (2021).

21. United States Centers for Disease Control and Prevention. CDC Expands Eligibility for COVID-19 Booster Shots (2021).

22. United States Centers for Disease Control and Prevention. Choosing Your COVID-19 Booster Shot. Vol. 2022 (2022). 
Fig. 1: Vaccine effectiveness of 2 doses of mRNA-1273 against omicron and delta variants by time since vaccination.



The figure depicts the waning effectiveness of 2 doses of mRNA-1273 vaccine against omicron infection (red line) and delta infection (blue line) within 365 days after vaccination. The vertical bar associated with each point estimate represents the $95 \%$ confidence interval of the vaccine effectiveness. 
Fig. 2: Vaccine effectiveness of 3 doses of mRNA-1273 against omicron and delta variants by time since vaccination among immunocompetent population.

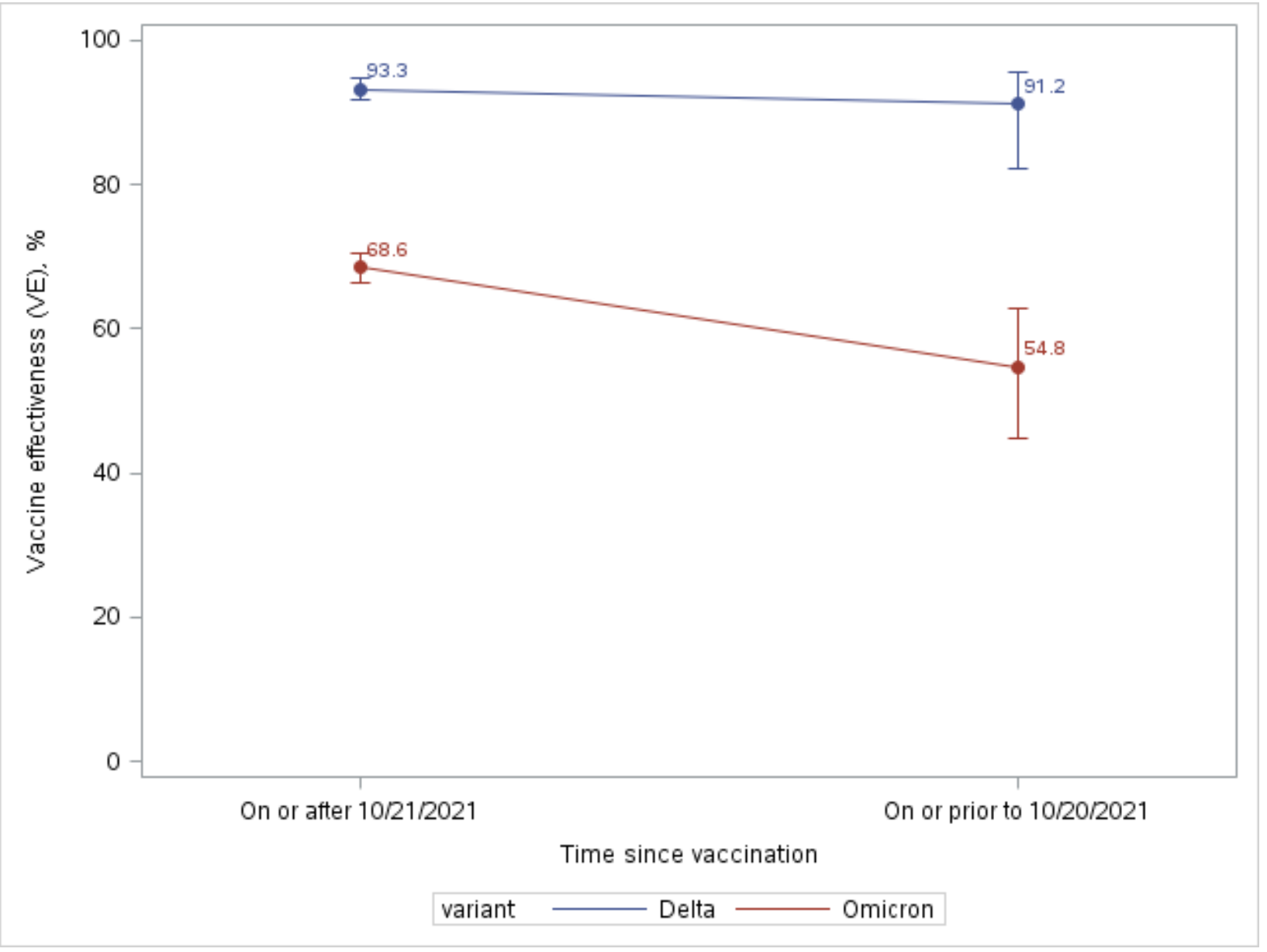

The figure depicts the effectiveness of 3 doses of mRNA-1273 vaccine against delta infection (blue line) and omicron infection (red line), comparing effectiveness of third doses received on or after 10/21/2021 with third doses received before that date. The vertical bar associated with each point estimate represents the 95\% confidence interval of the vaccine effectiveness. 
Table 1. Characteristics of SARS-CoV-2 cases and controls, by variant






\begin{tabular}{|c|c|c|c|c|c|c|c|c|c|c|c|c|}
\hline \multirow{3}{*}{$25-<30$} & 1,102 & 2,250 & & 5,130 & 10,513 & & 784 & 1675 & & 3106 & 6186 & \\
\hline & $(26.8 \%)$ & (27.3\%) & & $(26.5 \%)$ & (27.1\%) & & $(26.0 \%)$ & $(27.7 \%)$ & & $(27.7 \%)$ & (27.6\%) & \\
\hline & 838 & 1,635 & & 3,733 & 7,606 & & 599 & 1152 & & 2124 & 4306 & \\
\hline \multirow[t]{2}{*}{$30-<35$} & $(20.4 \%)$ & (19.9\%) & & $(19.2 \%)$ & (19.6\%) & & $(19.8 \%)$ & (19.1\%) & & (18.9\%) & $(19.2 \%)$ & \\
\hline & 411 & 860 & & 1,938 & 4,019 & & 304 & 586 & & 1054 & 2350 & \\
\hline \multirow[t]{2}{*}{$35-<40$} & (10.0\%) & (10.4\%) & & $(10.0 \%)$ & (10.4\%) & & (10.1\%) & $(9.7 \%)$ & & (9.4\%) & $(10.5 \%)$ & \\
\hline & 168 & 387 & & & 1,834 & & 117 & 248 & & & 1066 & \\
\hline \multirow[t]{2}{*}{$40-<45$} & (4.1\%) & $(4.7 \%)$ & & 914 (4.7\%) & $(4.7 \%)$ & & (3.9\%) & $(4.1 \%)$ & & $477(4.3 \%)$ & $(4.8 \%)$ & \\
\hline & 106 & 265 & & & 1,255 & & & 173 & & & & \\
\hline \multirow[t]{2}{*}{$\geq 45$} & $(2.6 \%)$ & (3.2\%) & & 601 (3.1\%) & (3.2\%) & & 67 (2.2\%) & $(2.9 \%)$ & & $277(2.5 \%)$ & 715 (3.2\%) & \\
\hline & 722 & 1,083 & & 3,045 & 5,057 & & 565 & 789 & & 1738 & 2732 & \\
\hline Unknown & (17.5\%) & (13.2\%) & & $(15.7 \%)$ & (13.0\%) & & $(18.7 \%)$ & (13.1\%) & & $(15.5 \%)$ & $(12.2 \%)$ & \\
\hline \multirow[t]{2}{*}{ Smoking ${ }^{\mathrm{b}}, \mathrm{n}(\%)$} & & & $\begin{array}{c}<0.01 / \\
0.12\end{array}$ & & & $\begin{array}{c}<0.01 / 1 \\
0.08\end{array}$ & & & $\begin{array}{c}<0.01 / \\
0.16\end{array}$ & & & $\begin{array}{c}<0.01 / 1 \\
0.10\end{array}$ \\
\hline & 2,855 & 5,942 & & 14,239 & 28,750 & & 2037 & 4374 & & 8172 & 16622 & \\
\hline \multirow{2}{*}{ No } & $(69.3 \%)$ & (72.2\%) & & (73.4\%) & (74.1\%) & & (67.4\%) & (72.4\%) & & (72.9\%) & (74.1\%) & \\
\hline & 672 & 1,425 & & 2,709 & 6,018 & & 510 & 1033 & & 1647 & 3658 & \\
\hline \multirow[t]{2}{*}{ Yes } & (16.3\%) & (17.3\%) & & (14.0\%) & (15.5\%) & & (16.9\%) & (17.1\%) & & (14.7\%) & $(16.3 \%)$ & \\
\hline & 590 & 867 & & 2,447 & 4,022 & & 474 & 635 & & 1398 & 2154 & \\
\hline \multirow[t]{2}{*}{ Unknown } & (14.3\%) & (10.5\%) & & (12.6\%) & (10.4\%) & & (15.7\%) & $(10.5 \%)$ & & (12.5\%) & (9.6\%) & \\
\hline & & & $<0.01 /$ & & & $<0.01 /$ & & & $<0.01 /$ & & & $<0.01 /$ \\
\hline \multirow{2}{*}{ Charlson comorbidity score ${ }^{a}, n(\%)$} & & & 0.12 & & & 0.11 & & & 0.12 & & & 0.12 \\
\hline & 3,324 & 6,321 & & 16,149 & 30,856 & & 2471 & 4689 & & 9084 & 17074 & \\
\hline \multirow[t]{2}{*}{0} & (80.7\%) & (76.8\%) & & (83.3\%) & $(79.5 \%)$ & & (81.8\%) & (77.6\%) & & (81.0\%) & (76.1\%) & \\
\hline & 480 & 1,007 & & 2,172 & 4,799 & & 337 & 731 & & 1254 & 3023 & \\
\hline \multirow[t]{2}{*}{1} & (11.7\%) & (12.2\%) & & (11.2\%) & (12.4\%) & & $(11.2 \%)$ & (12.1\%) & & $(11.2 \%)$ & (13.5\%) & \\
\hline & 313 & 906 & & 1,074 & 3,135 & & 213 & 622 & & & 2337 & \\
\hline \multirow[t]{2}{*}{$\geq 2$} & (7.6\%) & (11.0\%) & & (5.5\%) & (8.1\%) & & (7.1\%) & $(10.3 \%)$ & & $879(7.8 \%)$ & (10.4\%) & \\
\hline & & & $<0.01 /$ & & & $<0.01 /$ & & & $<0.01 /$ & & & $<0.01 /$ \\
\hline \multirow[t]{2}{*}{ Frailty index ${ }^{\mathrm{a}}, \mathrm{n}(\%)$} & & & 0.17 & & & 0.12 & & & 0.19 & & & 0.14 \\
\hline & 988 & 1,925 & & 4,926 & 9,615 & & 722 & 1451 & & 2729 & 5490 & \\
\hline \multirow[t]{2}{*}{ Quartile 1} & (24.0\%) & (23.4\%) & & (25.4\%) & (24.8\%) & & (23.9\%) & $(24.0 \%)$ & & (24.3\%) & $(24.5 \%)$ & \\
\hline & 1,249 & 2,013 & & 5,284 & 9,158 & & 935 & 1418 & & 3234 & 5371 & \\
\hline \multirow[t]{2}{*}{ Quartile 2} & $(30.3 \%)$ & (24.4\%) & & $(27.2 \%)$ & $(23.6 \%)$ & & $(31.0 \%)$ & $(23.5 \%)$ & & $(28.8 \%)$ & $(23.9 \%)$ & \\
\hline & 1,014 & 2,071 & & 4,952 & 9,700 & & 735 & 1537 & & 2831 & 5584 & \\
\hline Quartile 3 & $(24.6 \%)$ & (25.2\%) & & (25.5\%) & (25.0\%) & & $(24.3 \%)$ & $(25.4 \%)$ & & $(25.2 \%)$ & $(24.9 \%)$ & \\
\hline & 866 & 2,225 & & 4,233 & 10,317 & & 629 & 1636 & & 2423 & 5989 & \\
\hline Quartile 4 (most frail) & (21.0\%) & (27.0\%) & & $(21.8 \%)$ & $(26.6 \%)$ & & $(20.8 \%)$ & (27.1\%) & & $(21.6 \%)$ & $(26.7 \%)$ & \\
\hline Chronic diseases ${ }^{\mathrm{a}}, \mathrm{n}(\%)$ & & & & & & & & & & & & \\
\hline & & 252 & $<0.01 /$ & & & $<0.01 /$ & & 175 & $<0.01 /$ & & & $<0.01 /$ \\
\hline Kidney disease & $78(1.9 \%)$ & (3.1\%) & 0.08 & 205 (1.1\%) & $823(2.1 \%)$ & 0.09 & 56 (1.9\%) & $(2.9 \%)$ & 0.07 & $227(2.0 \%)$ & $613(2.7 \%)$ & 0.05 \\
\hline & & 180 & $<0.01 /$ & & & $<0.01 /$ & & 119 & $0.04 /$ & & & $<0.01 /$ \\
\hline Heart disease & $52(1.3 \%)$ & $(2.2 \%)$ & 0.07 & $160(0.8 \%)$ & $612(1.6 \%)$ & 0.07 & 41 (1.4\%) & $(2.0 \%)$ & 0.05 & $140(1.2 \%)$ & $386(1.7 \%)$ & 0.04 \\
\hline & 284 & 713 & $<0.01 /$ & 1,217 & 3,148 & $<0.01 /$ & 205 & 530 & $<0.01 /$ & & 2053 & $<0.01 /$ \\
\hline Lung disease & $(6.9 \%)$ & (8.7\%) & 0.07 & $(6.3 \%)$ & (8.1\%) & 0.07 & $(6.8 \%)$ & $(8.8 \%)$ & 0.07 & $774(6.9 \%)$ & $(9.2 \%)$ & 0.08 \\
\hline & 111 & 311 & $<0.01 /$ & & 1,161 & $<0.01 /$ & & 195 & $0.04 /$ & & & $<0.01 /$ \\
\hline Liver disease & (2.7\%) & (3.8\%) & 0.06 & $461(2.4 \%)$ & $(3.0 \%)$ & 0.04 & $74(2.4 \%)$ & $(3.2 \%)$ & 0.05 & $271(2.4 \%)$ & $730(3.3 \%)$ & 0.05 \\
\hline & 310 & 761 & $<0.01 /$ & 1,318 & 3,112 & $<0.01 /$ & 190 & 492 & $<0.01 /$ & & 2152 & $<0.01 /$ \\
\hline Diabetes & (7.5\%) & $(9.2 \%)$ & 0.06 & $(6.8 \%)$ & $(8.0 \%)$ & 0.05 & $(6.3 \%)$ & (8.1\%) & 0.07 & $831(7.4 \%)$ & (9.6\%) & 0.08 \\
\hline & & 267 & $<0.01 /$ & & 1,068 & $<0.01 /$ & & 245 & $<0.01 /$ & & & $<0.01 /$ \\
\hline Immunocompromised, n (\%) & $67(1.6 \%)$ & $(3.2 \%)$ & 0.10 & $332(1.7 \%)$ & $(2.8 \%)$ & 0.07 & $46(1.5 \%)$ & $(4.1 \%)$ & 0.15 & $274(2.4 \%)$ & $832(3.7 \%)$ & 0.07 \\
\hline HIV/AIDS & 3 & 27 & & 37 & 82 & & 2 & 28 & & 37 & 99 & \\
\hline
\end{tabular}


Leukemia/lymphoma, congenital and other

iencies, asplenia/hyposplenia

Organ transplant

Immunosuppressant medications

Autoimmune conditions ${ }^{\mathrm{a}}, \mathrm{n}(\%)$

Rheumatoid arthritis

Inflammatory bowel disease

Psoriasis and psoriatic arthritis

Multiple sclerosis

Systemic lupus erythematosus

Pregnant at specimen collection date, $\mathrm{n}$ (\%)

1st trimester

2nd trimester

3rd trimester

History of COVID-19 ${ }^{c}, \mathrm{n}(\%)$

History of SARS-CoV-2 molecular test ${ }^{\mathrm{c}}, \mathrm{n}(\%)$

Number of outpatient and virtual visits ${ }^{2}, n(\%)$

0

$1-4$

5-10

$\geq 11$

Number of Emergency Department visits ${ }^{2}, \mathrm{n}(\%)$

1

$\geq 2$

Number of hospitalizations ${ }^{\mathrm{a}}, \mathrm{n}(\%)$

\begin{tabular}{|c|c|c|c|c|c|c|c|c|c|c|c|}
\hline 28 & 86 & & 102 & 325 & & 17 & 84 & & 94 & 255 & \\
\hline 6 & 22 & & 15 & 75 & & 4 & 25 & & 29 & 84 & \\
\hline 38 & 168 & & 212 & 736 & & 29 & 158 & & 173 & 560 & \\
\hline $94(2.3 \%)$ & $\begin{array}{c}221 \\
(2.7 \%)\end{array}$ & $\begin{array}{c}0.18 / \\
0.03\end{array}$ & $351(1.8 \%)$ & $841(2.2 \%)$ & $\begin{array}{c}<0.01 / / \\
0.03\end{array}$ & $66(2.2 \%)$ & $\begin{array}{c}183 \\
(3.0 \%)\end{array}$ & $\begin{array}{c}0.02 / \\
0.05\end{array}$ & $253(2.3 \%)$ & $659(2.9 \%)$ & $\begin{array}{c}<0.01 / \\
0.04\end{array}$ \\
\hline 29 & 107 & & 125 & 350 & & 19 & 77 & & 100 & 282 & \\
\hline 22 & 52 & & 77 & 206 & & 17 & 52 & & 63 & 157 & \\
\hline 37 & 56 & & 129 & 241 & & 25 & 5 & & 74 & 197 & \\
\hline 7 & 13 & & 23 & 57 & & 5 & 9 & & 19 & 34 & \\
\hline 5 & $\begin{array}{c}21 \\
244\end{array}$ & $<0.01 /$ & 32 & $\begin{array}{c}98 \\
1213\end{array}$ & $<0.01 /$ & 3 & $\begin{array}{c}25 \\
187\end{array}$ & $<0.01 /$ & 33 & 88 & $<0.01 /$ \\
\hline $70(1.7 \%)$ & $(3.0 \%)$ & 0.08 & $343(1.8 \%)$ & (3.1\%) & 0.09 & 58 (1.9\%) & (3.1\%) & 0.08 & $224(2.0 \%)$ & 691 (3.1\%) & 0.07 \\
\hline 20 & 29 & & 68 & 175 & & 16 & 32 & & 40 & 78 & \\
\hline 22 & 67 & & 133 & 308 & & 20 & 51 & & 80 & 149 & \\
\hline 28 & 148 & & 142 & 730 & & 22 & 104 & & 104 & 464 & \\
\hline $\begin{array}{c}103 \\
(2.5 \%)\end{array}$ & $\begin{array}{c}1,637 \\
(19.9 \%)\end{array}$ & $\begin{array}{c}<0.01 / / \\
0.57\end{array}$ & $\begin{array}{c}2,639 \\
(13.6 \%)\end{array}$ & $\begin{array}{c}7,866 \\
(20.3 \%)\end{array}$ & $\begin{array}{c}<0.01 / / \\
0.18\end{array}$ & $92(3.0 \%)$ & $\begin{array}{c}1200 \\
(19.9 \%)\end{array}$ & $\begin{array}{c}<0.01 / / \\
0.55\end{array}$ & $\begin{array}{c}1731 \\
(15.4 \%)\end{array}$ & $\begin{array}{c}4062 \\
(18.1 \%)\end{array}$ & $\begin{array}{c}<0.01 / / \\
0.07\end{array}$ \\
\hline $\begin{array}{l}2,722 \\
(66.1 \%)\end{array}$ & $\begin{array}{c}6,456 \\
(78.4 \%)\end{array}$ & $\begin{array}{c}<0.01 / \\
0.28\end{array}$ & $\begin{array}{l}13,994 \\
(72.2 \%)\end{array}$ & $\begin{array}{l}28,950 \\
(74.6 \%)\end{array}$ & $\begin{array}{c}<0.01 / \\
0.06\end{array}$ & $\begin{array}{c}1954 \\
(64.7 \%)\end{array}$ & $\begin{array}{c}4824 \\
(79.8 \%)\end{array}$ & $\begin{array}{c}<0.01 / \\
0.34\end{array}$ & $\begin{array}{c}8199 \\
(73.1 \%)\end{array}$ & $\begin{array}{l}16894 \\
(75.3 \%)\end{array}$ & $\begin{array}{c}<0.01 / \\
0.05\end{array}$ \\
\hline & & $\begin{array}{c}<0.01 / \\
0.31\end{array}$ & & & $\begin{array}{c}<0.01 / \\
0.19\end{array}$ & & & $\begin{array}{c}<0.01 / \\
0.38\end{array}$ & & & $\begin{array}{c}<0.01 / \\
0.27\end{array}$ \\
\hline 501 & 571 & & 1,624 & 2,510 & & 453 & $\begin{array}{c}491 \\
4810)\end{array}$ & & 1202 & 1434 & \\
\hline (12.2\%) & $(6.9 \%)$ & & $(8.4 \%)$ & $(6.5 \%)$ & & (15.0\%) & $(8.1 \%)$ & & (10.7\%) & (6.4\%) & \\
\hline 1,450 & 2,220 & & 6,680 & 11,329 & & 1,121 & 1,630 & & 3,774 & 5,884 & \\
\hline (35.2\%) & (27.0\%) & & (34.4\%) & $(29.2 \%)$ & & (37.1\%) & (27.0\%) & & (33.6\%) & (26.2\%) & \\
\hline 1,109 & 2,401 & & 5,915 & 11,529 & & 731 & 1,656 & & 3,060 & 6,420 & \\
\hline (26.9\%) & (29.2\%) & & (30.5\%) & (29.7\%) & & (24.2\%) & (27.4\%) & & (27.3\%) & (28.6\%) & \\
\hline 1,057 & 3,042 & & 5176 & 13422 & & 716 & 2,265 & & 3,181 & 8,696 & \\
\hline (25.7\%) & (36.9\%) & & (26.7\%) & (34.6\%) & & (23.7\%) & (37.5\%) & & (28.4\%) & (38.8\%) & \\
\hline & & $\begin{array}{c}<0.01 / \\
0.16\end{array}$ & & & $\begin{array}{c}<0.01 / \\
0.13\end{array}$ & & & $\begin{array}{c}<0.01 / \\
0.13\end{array}$ & & & $\begin{array}{c}<0.01 / / \\
0.09\end{array}$ \\
\hline $\begin{array}{l}3,503 \\
\end{array}$ & 6,528 & & 16,378 & 31,250 & & 2,580 & 4,878 & & 9,362 & 18,132 & \\
\hline (85.1\%) & (79.3\%) & & (84.4\%) & (80.6\%) & & (85.4\%) & $(80.7 \%)$ & & (83.5\%) & $(80.8 \%)$ & \\
\hline 443 & 1,139 & & 2,270 & 5,066 & & 316 & 817 & & 1,366 & 2,903 & \\
\hline (10.8\%) & (13.8\%) & & (11.7\%) & (13.1\%) & & (10.5\%) & (13.5\%) & & (12.2\%) & (12.9\%) & \\
\hline 171 & 567 & & & 2,474 & & 125 & 347 & & & 1,399 & \\
\hline$(4.2 \%)$ & $(6.9 \%)$ & & 747 (3.9\%) & (6.4\%) & & (4.1\%) & $(5.7 \%)$ & & $489(4.4 \%)$ & (6.2\%) & \\
\hline & & $\begin{array}{c}<0.01 / / \\
0.09\end{array}$ & & & $\begin{array}{c}<0.01 / \\
0.10\end{array}$ & & & $\begin{array}{c}0.01 / \\
0.07\end{array}$ & & & $\begin{array}{c}<0.01 / / \\
0.08\end{array}$ \\
\hline $\begin{array}{c}3,923 \\
(95.3 \%)\end{array}$ & $\begin{array}{c}7,697 \\
(93.5 \%)\end{array}$ & & $\begin{array}{l}18,675 \\
(96.3 \%)\end{array}$ & $\begin{array}{c}36,624 \\
(94.4 \%)\end{array}$ & & $\begin{array}{c}2,873 \\
\text { (95.1\%) }\end{array}$ & $\begin{array}{c}5,670 \\
(93.8 \%)\end{array}$ & & $\begin{array}{l}10,743 \\
(95.8 \%)\end{array}$ & $\begin{array}{l}21,177 \\
(94.4 \%)\end{array}$ & \\
\hline 162 & 411 & & & 1,707 & & 123 & 280 & & & 1005 & \\
\hline (3.9\%) & $\begin{array}{c}(5.0 \%) \\
126\end{array}$ & & $630(3.2 \%)$ & $(4.4 \%)$ & & (4.1\%) & $(4.6 \%)$ & & $416(3.7 \%)$ & $(4.5 \%)$ & \\
\hline $32(0.8 \%)$ & $(1.5 \%)$ & & $90(0.5 \%)$ & 459 (1.2\%) & & $25(0.8 \%)$ & $92(1.5 \%)$ & & $58(0.5 \%)$ & $252(1.1 \%)$ & \\
\hline
\end{tabular}

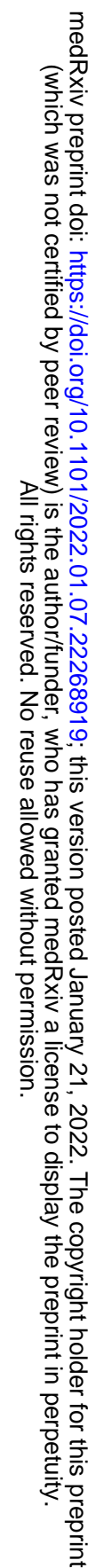


Preventive care ${ }^{\mathrm{a}}, \mathrm{n}(\%)$

Medicaid, $n$ (\%)

Neighborhood median household income, $n(\%)$

$$
<\$ 40,000
$$

$\$ 40,000-\$ 59,999$

$\$ 60,000-\$ 79,999$

$\$ 80,000+$

Unknown

KPSC physician/employee, $n(\%)$

Specimen type, $\mathrm{n}(\%)$

Nasopharyngeal/oropharyngeal swab

\begin{tabular}{|c|c|c|c|c|c|c|c|c|c|c|c|}
\hline $\begin{array}{c}2,186 \\
(53.1 \%)\end{array}$ & $\begin{array}{c}4,909 \\
(59.6 \%)\end{array}$ & $\begin{array}{c}<0.01 / 1 \\
0.13\end{array}$ & $\begin{array}{c}10,773 \\
(55.5 \%)\end{array}$ & $\begin{array}{c}23,352 \\
(60.2 \%)\end{array}$ & $\begin{array}{c}<0.01 / 1 \\
0.09\end{array}$ & $\begin{array}{c}1,450 \\
(48.0 \%)\end{array}$ & $\begin{array}{c}3,660 \\
(60.6 \%)\end{array}$ & $\begin{array}{c}<0.01 / \\
0.25\end{array}$ & $\begin{array}{c}6,114 \\
(54.5 \%)\end{array}$ & $\begin{array}{l}14,617 \\
(65.2 \%)\end{array}$ & $\begin{array}{c}<0.01 / \\
0.22\end{array}$ \\
\hline 391 & 844 & $0.19 /$ & 1,897 & 4,461 & $<0.01 /$ & 310 & 581 & $0.33 /$ & 1,187 & 2,425 & $0.53 /$ \\
\hline \multirow[t]{2}{*}{$(9.5 \%)$} & (10.3\%) & 0.03 & $(9.8 \%)$ & (11.5\%) & 0.06 & (10.3\%) & (9.6\%) & 0.02 & (10.6\%) & (10.8\%) & 0.01 \\
\hline & & $\begin{array}{c}0.05 / \\
0.06\end{array}$ & & & $\begin{array}{c}<0.01 / 1 \\
0.05\end{array}$ & & & $\begin{array}{c}<0.01 / \\
0.09\end{array}$ & & & $\begin{array}{c}0.03 / \\
0.04\end{array}$ \\
\hline 179 & 402 & & & 1,902 & & 129 & 243 & & & 1070 & \\
\hline (4.3\%) & (4.9\%) & & $812(4.2 \%)$ & (4.9\%) & & (4.3\%) & $(4.0 \%)$ & & $458(4.1 \%)$ & $(4.8 \%)$ & \\
\hline 712 & 1,580 & & 3,856 & 8,082 & & 494 & 1171 & & 2,175 & 4,392 & \\
\hline (17.3\%) & (19.2\%) & & (19.9\%) & $(20.8 \%)$ & & (16.4\%) & (19.4\%) & & (19.4\%) & (19.6\%) & \\
\hline 1,097 & 2,121 & & 5,146 & 9,948 & & 817 & 1,483 & & 2,931 & 5,740 & \\
\hline (26.6\%) & (25.8\%) & & $(26.5 \%)$ & (25.6\%) & & (27.0\%) & (24.5\%) & & (26.1\%) & (25.6\%) & \\
\hline 2,126 & 4,123 & & 9,563 & 18,817 & & 1,579 & 3,141 & & 5,636 & 11,211 & \\
\hline (51.6\%) & (50.1\%) & & $(49.3 \%)$ & $(48.5 \%)$ & & (52.3\%) & $(52.0 \%)$ & & (50.2\%) & (50.0\%) & \\
\hline $3(0.1 \%)$ & $8(0.1 \%)$ & & $18(0.1 \%)$ & $41(0.1 \%)$ & & $2(0.1 \%)$ & $4(0.1 \%)$ & & $17(0.2 \%)$ & $21(0.1 \%)$ & \\
\hline 129 & 609 & $<0.01 /$ & & 1759 & $0.04 /$ & & 558 & $<0.01 /$ & & 1,176 & $<0.01 /$ \\
\hline \multirow[t]{3}{*}{ (3.1\%) } & (7.4\%) & 0.19 & $806(4.2 \%)$ & $(4.5 \%)$ & 0.02 & $85(2.8 \%)$ & (9.2\%) & 0.27 & $480(4.3 \%)$ & $(5.2 \%)$ & 0.05 \\
\hline & & $<0.01 /$ & & & $<0.01 /$ & & & $<0.01 /$ & & & $<0.01 /$ \\
\hline & & 0.39 & & & 0.21 & & & 0.47 & & & 0.17 \\
\hline 3,627 & 5,990 & & 17,162 & 31,379 & & 2,607 & 4,042 & & 9,513 & 17,523 & \\
\hline (88.1\%) & $(72.7 \%)$ & & (88.5\%) & $(80.9 \%)$ & & (86.3\%) & (66.9\%) & & $(84.8 \%)$ & (78.1\%) & \\
\hline 490 & 2,244 & & 2,233 & 7,411 & & 414 & 2,000 & & 1,704 & 4,911 & \\
\hline (11.9\%) & $(27.3 \%)$ & & (11.5\%) & (19.1\%) & & (13.7\%) & (33.1\%) & & (15.2\%) & (21.9\%) & \\
\hline
\end{tabular}

Sefined in the one year prior to specimen collection da

${ }^{b}$ Defined in the 2 years prior to specimen collection date

'Defined based on all available medical records from March 1, 2020, to specimen collection date

Medical center area not shown. There were differences in the distribution of the vaccinated and unvaccinated individuals across the 19 medical center areas.

$\mathrm{N} / \mathrm{A}=$ not applicable 
Table 2. Vaccine effectiveness of mRNA-1273 against infection and hospitalization with delta or omicron variants

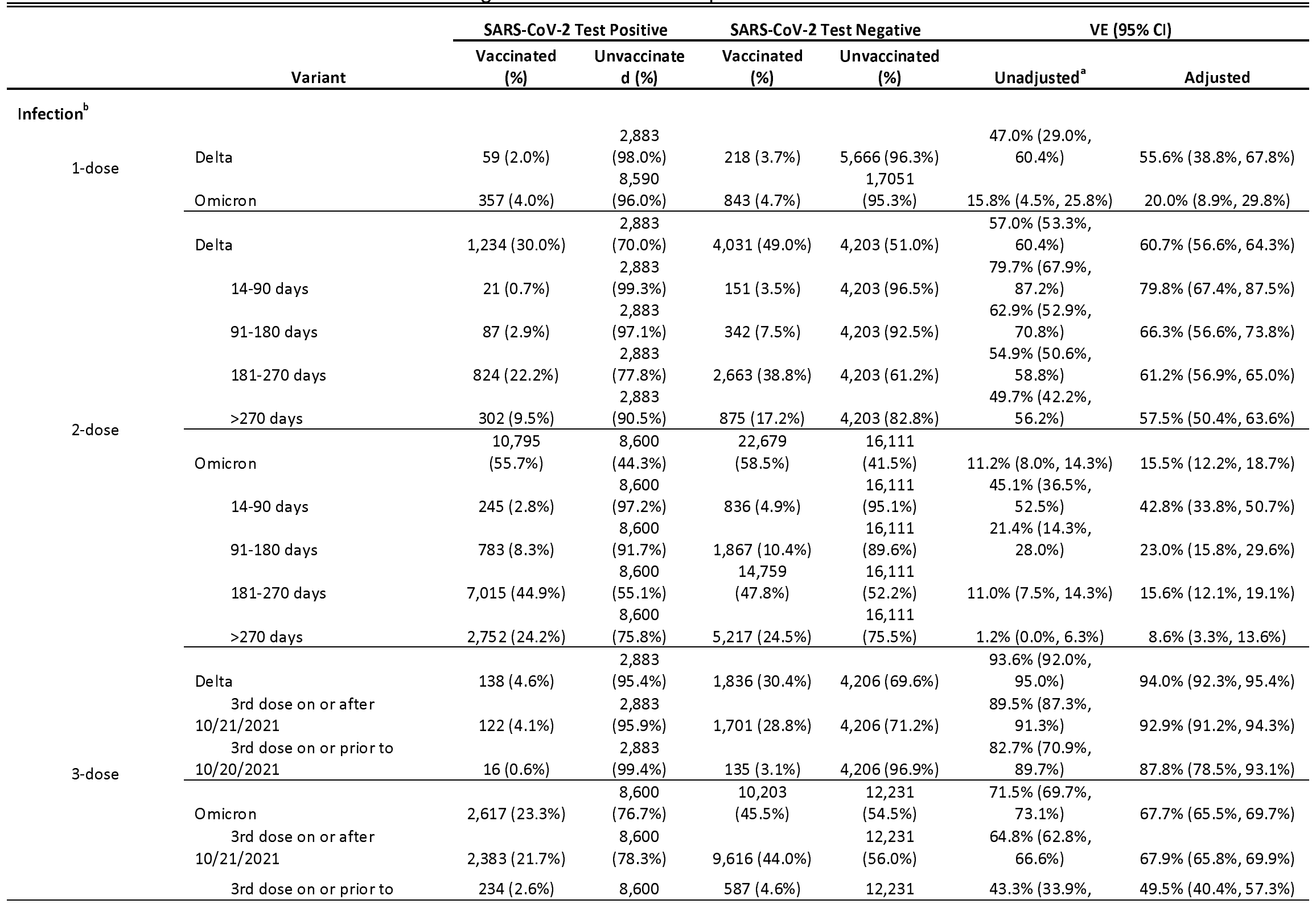




\begin{tabular}{|c|c|c|c|c|c|c|c|}
\hline & $10 / 20 / 2021$ & & $(97.4 \%)$ & & (95.4\%) & $51.4 \%)$ & \\
\hline \multirow{7}{*}{$\begin{array}{l}\text { 3-dose excluding } \\
\text { immunocompromise } \\
\text { d individuals }\end{array}$} & Delta & $124(4.2 \%)$ & $\begin{array}{c}2,851 \\
(95.8 \%)\end{array}$ & $1,708(29.5 \%)$ & $4,089(70.5 \%)$ & $\begin{array}{c}89.6 \%(87.4 \% \\
91.4 \%)\end{array}$ & $93.2 \%(91.6 \%, 94.5 \%)$ \\
\hline & $3 r d$ dose on or after & & 2,851 & & & $89.9 \%(87.7 \%$, & \\
\hline & $10 / 21 / 2021$ & $114(3.8 \%)$ & $(96.2 \%)$ & $1,623(28.4 \%)$ & $4,089(71.6 \%)$ & $91.7 \%)$ & $93.3 \%(91.7 \%, 94.7 \%)$ \\
\hline & $\begin{array}{l}\text { 3rd dose on or prior to } \\
10 / 20 / 2021\end{array}$ & $10(0.3 \%)$ & $\begin{array}{c}2,851 \\
(99.7 \%)\end{array}$ & $85(2.0 \%)$ & $4,089(98.0 \%)$ & $\begin{array}{c}83.1 \%(67.5 \% \\
91.3 \%)\end{array}$ & $91.2 \%(82.3 \%, 95.6 \%)$ \\
\hline & Omicron & $2,464(22.5 \%)$ & $\begin{array}{c}8,479 \\
(77.5 \%)\end{array}$ & $9,677(44.8 \%)$ & $\begin{array}{l}11,925 \\
(55.2 \%)\end{array}$ & $\begin{array}{c}64.2 \%(62.3 \% \\
66.0 \%)\end{array}$ & $68.2 \%(66.1 \%, 70.2 \%)$ \\
\hline & $\begin{array}{l}\text { 3rd dose on or after } \\
10 / 21 / 2021\end{array}$ & $2,306(21.4 \%)$ & $\begin{array}{c}8,479 \\
(78.6 \%)\end{array}$ & $9,282(43.8 \%)$ & $\begin{array}{l}11,925 \\
(56.2 \%)\end{array}$ & $\begin{array}{c}65.1 \%(63.1 \% \\
66.9 \%)\end{array}$ & $68.6 \%(66.5 \%, 70.6 \%)$ \\
\hline & $\begin{array}{l}\text { 3rd dose on or prior to } \\
10 / 20 / 2021\end{array}$ & $158(1.8 \%)$ & $\begin{array}{c}8,479 \\
(98.2 \%) \\
\end{array}$ & $395(3.2 \%)$ & $\begin{array}{c}11,925 \\
(96.8 \%) \\
\end{array}$ & $\begin{array}{c}43.7 \%(32.2 \% \\
53.3 \%) \\
\end{array}$ & $54.8 \%(44.9 \%, 62.9 \%)$ \\
\hline \multicolumn{8}{|l|}{ Hospitalization $^{c}$} \\
\hline \multirow{2}{*}{ 1-dose } & Delta & $1(1.3 \%)$ & $79(98.8 \%)$ & $10(6.3 \%)$ & $150(93.8 \%)$ & $82.2 \%(0.0 \%, 97.8 \%)$ & $76.1 \%(0.0 \%, 98.2 \%)$ \\
\hline & Omicron & $0(0.0 \%)$ & $14(100.0 \%)$ & $2(7.1 \%)$ & $26(92.9 \%)$ & $\begin{array}{l}100.0 \%(\mathrm{~N} / \mathrm{A}) \\
95.9 \%(86.9 \% \text {, }\end{array}$ & $N / A$ \\
\hline \multirow[t]{2}{*}{ 2-dose } & Delta & $4(4.8 \%)$ & 79 (95.2\%) & $94(56.6 \%)$ & $72(43.4 \%)$ & $\begin{array}{c}98.7 \%) \\
81.1 \%(29.8 \%,\end{array}$ & $98.5 \%(92.0 \%, 99.7 \%)$ \\
\hline & Omicron & $7(33.3 \%)$ & $14(66.7 \%)$ & $28(66.7 \%)$ & $14(33.3 \%)$ & $94.9 \%)$ & $74.8 \%(2.4 \%, 93.5 \%)$ \\
\hline \multirow{2}{*}{ 3-dose } & Delta & $1(1.3 \%)$ & $79(98.8 \%)$ & $69(43.1 \%)$ & $91(56.9 \%)$ & $\begin{array}{c}98.3 \%(87.7 \% \\
99.8 \%)\end{array}$ & $\begin{array}{c}99.6 \%(95.7 \% \\
100.0 \%)\end{array}$ \\
\hline & Omicron & $4(22.2 \%)$ & $14(77.8 \%)$ & $26(72.2 \%)$ & $10(27.8 \%)$ & $\begin{array}{c}89.0 \%(58.5 \% \\
97.1 \%)\end{array}$ & $\begin{array}{c}99.7 \%(82.2 \% \\
100.0 \%)\end{array}$ \\
\hline
\end{tabular}

${ }^{a}$ Models for time since vaccination analyses and 3-dose hospitalization analyses are unconditional logistic models, and the rest are conditional logistic models conditioned on matched pairs.

${ }^{\mathrm{b}}$ Model adjustment - Refer to Supplementary Table 1 for list of the covariates:

Model for 1-dose delta variant adjusted for covariates: 4, 5, 7, 13, 16, 17, 18, 19, 24, 25, 26.

Model for 2-dose delta variant adjusted for covariates: 4, 5, 6, 7, 13, 16, 17, 18, 19, 21, 24, 25, 26.

Model for 3-dose delta variant adjusted for covariates: 4, 5, 6, 7, 13, 16, 17, 18, 19, 21, 24, 25, 26.

Model for 1-dose omicron variant adjusted for covariates: $6,15,16,18,19,20,25,26$

Model for 2-dose omicron variant adjusted for covariates $6,7,16,18,19,20,25,26$.

Model for 3-dose omicron variant adjusted for covariates: 4, 6, 7, 18, 21, 25, 26.

Models for time since vaccination analyses are unconditional logistic models, and are adjusted for matching variables age groups, sex, and race/ethnicity in addition to the covariates adjusted in conditional models.

'Model adjustment:

Model for 1-dose delta variant adjusted for covariates: 4, 12, 16, 17, 21.

Model for 2-dose delta variant adjusted for covariates: 4, 12, 16, 17, 21.

Model for 3-dose delta variant is unconditional model and adjusted for covariates: 1, 2, 3, 4, 12, 16, 17, 21.

Model for 2-dose omicron variant adjusted for covariates: 16 and 22. 
Model for 3-dose omicron variant is unconditional model and adjusted for covariates: 1, 2, 3, 5, 19. 
Table 3. Vaccine effectiveness of 3 doses of mRNA-1273 against infection with delta or omicron variants by subgroup

\begin{tabular}{|c|c|c|c|c|c|c|}
\hline \multirow[b]{2}{*}{ Variant $^{a}$} & \multicolumn{2}{|c|}{ SARS-CoV-2 Test Positive } & \multicolumn{2}{|c|}{ SARS-CoV-2 Test Negative } & \multicolumn{2}{|c|}{ VE $(95 \% \mathrm{Cl})$} \\
\hline & Vaccinated (\%) & Unvaccinated (\%) & Vaccinated (\%) & Unvaccinated (\%) & Unadjusted $^{a}$ & Adjusted $^{\mathbf{b}}$ \\
\hline \multicolumn{7}{|l|}{ Delta } \\
\hline \multicolumn{7}{|l|}{ Age at specimen collection date } \\
\hline & & 2,694 & 1,470 & & & \\
\hline$<65$ & $94(3.4 \%)$ & $(96.6 \%)$ & $(26.4 \%)$ & $4,106(73.6 \%)$ & $93.3 \%(91.3 \%, 94.8 \%)$ & $93.6 \%(91.5 \%, 95.2 \%)$ \\
\hline$\geq 65$ & $44(18.9 \%)$ & $189(81.1 \%)$ & $366(78.5 \%)$ & $100(21.5 \%)$ & $95.0 \%(91.1 \%, 97.1 \%)$ & $97.3 \%(94.2 \%, 98.7 \%)$ \\
\hline \multicolumn{7}{|l|}{ Sex } \\
\hline & & 1,519 & & & & \\
\hline Female & $75(4.7 \%)$ & $(95.3 \%)$ & $969(30.4 \%)$ & $2,219(69.6 \%)$ & $93.2 \%(90.7 \%, 95.0 \%)$ & $94.0 \%(91.6 \%, 95.8 \%)$ \\
\hline & & 1,364 & & & & \\
\hline Male & $63(4.4 \%)$ & $(95.6 \%)$ & $867(30.4 \%)$ & $1,987(69.6 \%)$ & $94.2 \%(91.7 \%, 95.9 \%)$ & $94.2 \%(91.3 \%, 96.1 \%)$ \\
\hline \multicolumn{7}{|l|}{ Race/ethnicity } \\
\hline \multirow{3}{*}{ Hispanic } & & 1,240 & & & & \\
\hline & $39(3.0 \%)$ & $(97.0 \%)$ & $577(22.6 \%)$ & $1,981(77.4 \%)$ & $92.4 \%(88.7 \%, 94.8 \%)$ & $92.2 \%(88.0 \%, 94.9 \%)$ \\
\hline & & 1,643 & 1,259 & & & \\
\hline Non-Hispanic and others & $99(5.7 \%)$ & $(94.3 \%)$ & $(36.1 \%)$ & $2,225(63.9 \%)$ & $94.2 \%(92.2 \%, 95.7 \%)$ & $94.8 \%(92.8 \%, 96.2 \%)$ \\
\hline \multicolumn{7}{|l|}{ Immunocompromised status } \\
\hline \multirow[t]{2}{*}{ Yes } & $14(30.4 \%)$ & $32(69.6 \%)$ & $128(52.2 \%)$ & $117(47.8 \%)$ & $60.0 \%(21.4 \%, 79.7 \%)$ & $75.0 \%(38.3 \%, 89.9 \%)$ \\
\hline & & 2,851 & 1,708 & & & \\
\hline No & $124(4.2 \%)$ & $(95.8 \%)$ & $(29.5 \%)$ & $4,089(70.5 \%)$ & $89.6 \%(87.4 \%, 91.4 \%)$ & $93.2 \%(91.6 \%, 94.5 \%)$ \\
\hline \multicolumn{7}{|l|}{ Omicron } \\
\hline \multicolumn{7}{|l|}{ Age at specimen collection date } \\
\hline & 1,943 & 8,335 & 8,573 & 11,983 & & \\
\hline$<65$ & $(18.9 \%)$ & (81.1\%) & $(41.7 \%)$ & $(58.3 \%)$ & $72.2 \%(70.4 \%, 73.9 \%)$ & $68.6 \%(66.3 \%, 70.7 \%)$ \\
\hline & & & 1,630 & & & \\
\hline$\geq 65$ & $674(71.8 \%)$ & $265(28.2 \%)$ & $(86.8 \%)$ & $248(13.2 \%)$ & $61.7 \%(53.2 \%, 68.6 \%)$ & $63.6 \%(53.8 \%, 71.4 \%)$ \\
\hline \multicolumn{7}{|l|}{ Sex } \\
\hline \multirow{3}{*}{ Female } & 1,529 & 4,816 & 5,862 & & & \\
\hline & $(24.1 \%)$ & $(75.9 \%)$ & $(46.2 \%)$ & $6,828(53.8 \%)$ & $70.4 \%(67.9 \%, 72.6 \%)$ & $67.4 \%(64.6 \%, 70.1 \%)$ \\
\hline & 1,088 & 3,784 & 4,341 & & & \\
\hline Male & $(22.3 \%)$ & $(77.7 \%)$ & $(44.6 \%)$ & $5,403(55.4 \%)$ & $72.9 \%(70.3 \%, 75.3 \%)$ & $68.0 \%(64.5 \%, 71.2 \%)$ \\
\hline Race/ethnicity & & & & & & \\
\hline
\end{tabular}




\begin{tabular}{|c|c|c|c|c|c|c|}
\hline & & 4,157 & 3,976 & & & \\
\hline \multirow[t]{2}{*}{ Hispanic } & $970(18.9 \%)$ & (81.1\%) & $(38.8 \%)$ & $6,278(61.2 \%)$ & $69.6 \%(66.7 \%, 72.2 \%)$ & $65.4 \%(61.7 \%, 68.7 \%)$ \\
\hline & 1,647 & 4,443 & 6,227 & & & \\
\hline Non-Hispanic and others & $(27.0 \%)$ & $(73.0 \%)$ & $(51.1 \%)$ & $5,953(48.9 \%)$ & $72.8 \%(70.5 \%, 74.9 \%)$ & $69.3 \%(66.5 \%, 71.9 \%)$ \\
\hline \multicolumn{7}{|l|}{ Immunocompromised status } \\
\hline \multirow[t]{2}{*}{ Yes } & $153(55.8 \%)$ & $121(44.2 \%)$ & $526(63.2 \%)$ & $306(36.8 \%)$ & $26.4 \%(3.0 \%, 44.2 \%)$ & $21.7 \%(0.0 \%, 45.0 \%)$ \\
\hline & 2,464 & 8,479 & 9,677 & 11,925 & & \\
\hline No & $(22.5 \%)$ & $(77.5 \%)$ & $(44.8 \%)$ & $(55.2 \%)$ & $64.2 \%(62.3 \%, 66.0 \%)$ & $68.2 \%(66.1 \%, 70.2 \%)$ \\
\hline
\end{tabular}

${ }^{a}$ Models for immunocompromised status subgroup analyses are unconditional logistic models, and the rest are conditional logistic models conditioned on matched pairs.

${ }^{b}$ Model adjustment - Refer to Supplementary Table 1 for list of the covariates:

Models for delta variant adjusted for covariates: 4, 5, 6, 7, 13, 16, 17, 18, 19, 21, 24, 25, 26.

Models for omicron variant adjusted for covariates: 4, 6, 7, 18, 21, 25, 26.

Models for immunocompromised status analyses are adjusted for matching variables age groups, sex, and race/ethnicity in addition to the covariates adjusted in

conditional models.

Model for delta variant in immunocompromised subgroup adjusted for covariates: 1, 2, 3, 4, 5, 6, 7, 13, 16, 17, $18,19,21,24,25$. 